\title{
Experimental Investigation of WEDM Variables on Surface Roughness of AISI H13
}

\author{
Harvinder Singh, Khushdeep Goyal", Parlad Kumar \\ ${ }^{1}$ Department of Mechanical Engineering, Punjabi University, Patiala, 147001, Punjab, India \\ *Corresponding Author: khushgoyal@yahoo.com
}

Copyright $@ 2013$ Horizon Research Publishing All rights reserved.

\begin{abstract}
The objective of this paper is to experimentally investigate the effects of various Wire Electrical Discharge Machining variables on Surface Roughness of AISI H13 using ANOVA method. The effect of all the input parameters on the output responses have been analyzed using analysis of variance (ANOVA). Plots of $\mathrm{S} / \mathrm{N}$ ratio have been used to determine the best relationship between the responses and the input parameters. The optimum set of input parameters for minimum surface roughness has been determined. It has been found that wire type and pulse on time are most significant factors for surface roughness
\end{abstract}

Keywords WEDM, ANOVA, Surface Roughness, S/N Ratio, Process Parameters

\section{Introduction}

The AISI H13 has been used as workpiece material, which is the most popular and most versatile, hot work tool steel, providing a good balance of toughness, heat check resistance and high temperature strength in addition to moderate wear resistance. Taguchi's L27 Orthogonal Array is used to conduct experiments, which correspond to randomly chosen different combination of process parameters: wire type, pulse on time, pulse off time, peak current, servo voltage, wire tension, wire feed rate, servo feed rate, flushing pressure each to be varied in three different levels.

\section{Literature Survey}

Hascalyk et al., [1] conducted experiment to study wire electric discharge machining of AISI D5 tool steel. Experimentally it was found that the micro-hardness distribution below the surface with increased dielectric fluid pressure was not changed but the hardness of surface increased slightly. Wire speed do not had any effect on micro-hardness distribution of specimen. The cutting surface of all specimens shows red hardness than the bulk material because of white layer, while the heat affected zone was softer in quenched and tempered specimen because of over tempered martensite. The models for co-relating the inter-relationships of various WEDM machining parameters of Inconel 601 material was established using Response Surface Methodology [2]. Results showed that the volumetric material removal rate generally increases with the increase of the peak current value and flushing pressure. Wear ratio increases with increase of peak current. Surface Roughness increases with the increase of peak current and decreases with increase of duty factor and wire tension. Yuan et al., [3] used a predictive approach based on Gaussian Process Regression in order to develop a reliable multi-objective optimization to optimize the HS-WEDM process. The authors used mean current, on time and off time as process parameters and MRR and SR were chosen as machining performance parameters. The experiments were conducted on DK-7732C2 WEDM-HS machine. The maximum MRR was $20 \mathrm{~mm} 2 / \mathrm{min}$ and SR was less than 2.5 $\mu \mathrm{m}$. Singh and Garg [4] carried out Wire Electric Discharge Machining of H-11 hot die tool steel material on Electronica Sprintcut WEDM machine. They investigated the effect of pulse on time, pulse off time, gap voltage, peak current, wire feed, wire tension on material removal rate of hot die steel (H-11) using one variable at a time approach. The optimum parameters were predicted to maximize the material removal rate. Rao et al., [5] studied the effect of WEDM conditions on surface roughness for a parametric optimization using Taguchi Method. The minimum SR was obtained at low peak current $(10 \mathrm{~A})$ and low pulse on time $(105 \mu \mathrm{s})$. The minimum SR was obtained at high wire tension $(10 \mathrm{~kg}-\mathrm{f})$ and low spark gap voltage $(8 \mathrm{~V})$. The proposed regression model (with high correlation co-efficient) successfully predicted the parametric values in the machining of Aluminium BIS-24345 alloy. Alias et al., [6] investigated the influence of feed rate on the performance of WEDM on Titanium Ti-Al-4V. It was found that smoother surface which can be obtained at high machine feed rate. When wire tension is increased, it reduces the vibration and improved the machined surface quality. The authors found that low machine feed rate gives bigger crater as compared to high feed rate and vice versa.

The optimal set of parameters has also been predicted to 
maximize the material removal rate by authors [7]. Results showed that the better parameter setting was pulse on time 24 $\mu \mathrm{s}$, pulse off time $6 \mu \mathrm{s}$, bed speed $35 \mu \mathrm{m} / \mathrm{s}$ and current 5 Ampere to obtain maximum material removal rate. The strength order of parameter are found from response table is current, pulse on time, bed speed and pulse off time. Muthuraman et al., [8] studied the influence of Process Variable during WEDM of O1 Steel. It was found that surface Roughness decreases with increase in Pulse on time. Pulse on time does not affect the dimensional deviation largely. Wear ratio increases with the increase in Pulse on time. MRR initially decreases and then increases significantly. Surface Roughness increases with increase in Pulse off time. The effect of Pulse off time on dimensional deviation was negligible. The ANOVA was carried out to study the effect of process parameters on process performance and it was shown that pulse-on time, pulse-off time and peak current were most significant parameters [9]. An optimum parametric combination for the maximum material removal rate was obtained by using signal-to-noise ratio.

\section{Objectives}

The following objectives have been decided for this research work:-

- To find out the effect of different process parameters on surface roughness of the machined specimen.

- To work out the optimum set of input parameters for minimum surface roughness by using ANOVA method.

- To check the validity by conducting confirmation experiments.
The experiments were carried out on a WEDM machine, model: ELEKTRA SPRINTCUT 734 of Electronica Machine Tools Ltd., Installed at Central Tool Room, Ludhiana, Punjab, India.

The aisi H13 hot work tool steel specimens of $50 \mathrm{~mm}$ length, $27 \mathrm{~mm}$ width and $15 \mathrm{~mm}$ thickness have been used as workpiece material for the present investigation. The Photographic view of workpiece specimen is shown in Figure 1.

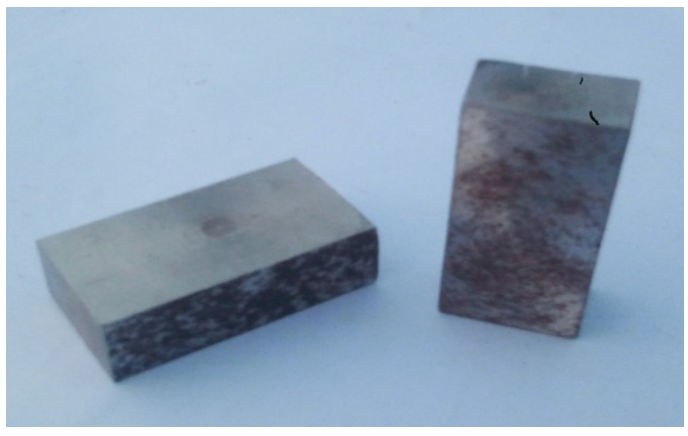

Figure 1. A Photographic views of a workpiece specimen.

\subsection{Input Factors and Their Parameters}

In this study the factors which mainly affect the response parameters (surface roughness and material removal rate) with their levels were taken. Some of the factors like number of passes, thickness of workpiece, angle of cut were kept constant during the experimental study. The various parameters which were taken for experimental study were type of wire, pulse on time, pulse off time, peak current, servo voltage, wire tension, wire feed rate, servo feed rate, flushing pressure. Three levels of each parameter were taken for the experimental operation. Table 1 shows various levels of input factors.

\section{Experimentation}

Table 1. Input factors and their levels

\begin{tabular}{|c|c|c|c|c|c|c|}
\hline S.No. & Paramater & Symbol & Level 1 & Level 2 & Level 3 & Units \\
\hline 1. & Wire Type & ---- & Brass & Diffused & Coated & \\
\hline 2. & Pulse On Time & TON & 117 & 122 & 127 & $\mu \mathrm{s}$ \\
\hline 3. & Pulse Off Time & TOFF & 50 & 52 & 54 & $\mu \mathrm{s}$ \\
\hline 4. & Peak Current & PC & 210 & 220 & 230 & Ampere \\
\hline 5. & Servo Voltage & SV & 20 & 25 & 30 & Volts \\
\hline 6. & Wire Tension & WT & 6 & 7 & 8 & $\mathrm{Kg}-\mathrm{f}$ \\
\hline 7. & Wire Feed Rate & WF & 4 & 5 & 6 & $\mathrm{~m} / \mathrm{min}$ \\
\hline 8. & Servo Feed setting & SF & 2100 & 2110 & 2120 & $\mathrm{~mm} / \mathrm{min}$ \\
\hline 9. & Flushing Pressure & FP & 10 & 12 & 14 & $\mathrm{Kg} / \mathrm{cm}^{2}$ \\
\hline
\end{tabular}


The experiment was designed with L27 orthogonal array, 27 workpieces were machined to complete 27 experimental runs. For each experiment the level of input factors were adjusted on the machine according to their values in the orthogonal array.

\section{Results and Discussion}

\subsection{Analysis of S/N Ratio for Surface Roughness}

The results observed for the surface roughness are shown in Table 2. In this table, value of surface roughness is given for each work and also the calculate value of $\mathrm{S} / \mathrm{N}$ ratio in last column for all 27 treatment conditions. In this design situation, surface roughness is find out with lower is better, which is a logarithmic function based on mean square deviation. The experimental results for surface roughness were analyzed using ANOVA calculations and are given in table 3.

Table 2. Result for Surface Roughness (Ra)

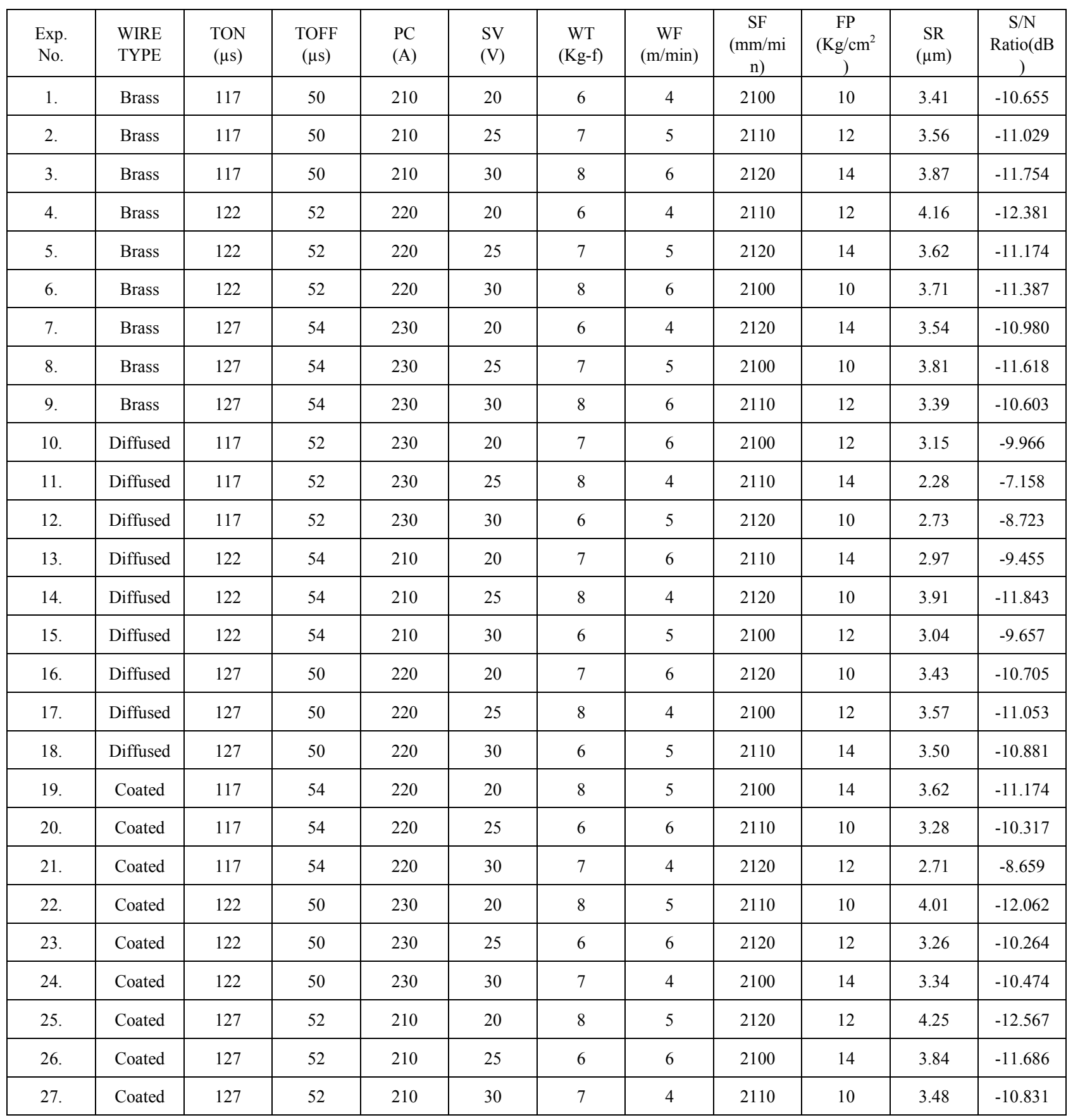


Table 3. Analysis of Variance for $\mathrm{S} / \mathrm{N}$ ratio for Surface Roughness (Ra)

\begin{tabular}{|c|c|c|c|c|c|c|c|}
\hline S. No. & Source & $\begin{array}{c}\text { Sum of } \\
\text { Squares }\end{array}$ & $\begin{array}{c}\text { Degree of } \\
\text { Freedom }\end{array}$ & $\begin{array}{c}\text { Mean } \\
\text { Square }\end{array}$ & F- ratio & Status & $\begin{array}{c}\text { Percentage } \\
\text { Contribution }\end{array}$ \\
\hline $\mathbf{1 .}$ & WIRE TYPE & 8.658 & 2 & 4.329 & 3.790 & Insignificant & $22.86 \%$ \\
\hline $\mathbf{2 .}$ & PULSE ON TIME & 8.249 & 2 & 4.124 & 3.611 & Insignificant & $21.78 \%$ \\
\hline $\mathbf{3 .}$ & PULSE OF TIME & 1.198 & 2 & 0.599 & 0.524 & Insignificant & $3.16 \%$ \\
\hline $\mathbf{4 .}$ & PEAK CURRENT & 3.549 & 2 & 1.774 & 1.553 & Insignificant & $9.37 \%$ \\
\hline $\mathbf{5 .}$ & SERVO VOLTAGE & 2.710 & 2 & 1.355 & 1.186 & Insignificant & $7.15 \%$ \\
\hline $\mathbf{6 .}$ & $\begin{array}{c}\text { WIRE } \\
\text { TENSION }\end{array}$ & 1.907 & 2 & 0.953 & 0.834 & Insignificant & $5.03 \%$ \\
\hline $\mathbf{7 .}$ & WIRE FEED RATE & 1.314 & 2 & 0.657 & 0.575 & Insignificant & $3.46 \%$ \\
\hline $\mathbf{8 .}$ & SERVO FEED RATE & 0.499 & 2 & 0.249 & 0.218 & Insignificant & $1.31 \%$ \\
\hline $\mathbf{9 .}$ & $\begin{array}{c}\text { FLUSHING } \\
\text { PRESSURE }\end{array}$ & 0.647 & 2 & 0.323 & 0.282 & Insignificant & $1.71 \%$ \\
\hline & ERROR & 9.143 & 8 & 1.142 & & & $24.14 \%$ \\
\hline
\end{tabular}

The F-values given in the table suggests the significance of the factors on the desired characteristic. The principle of $F$ test is that larger the $\mathrm{F}$ value more is the significance of factor. In these experiments the $F_{0.05,2,8}$ table value, determines significance of a factor at $95 \%$ confidence level, if it is greater than 4.46 . Since $\mathrm{F}_{0.05,2,8}=4.46$, none of the effects are significant. Using the pooling rule, owing to lower values the SS Servo Feed Rate, SS Flushing Pressure can be pooled into the error term leaving the seven effects in the pooled ANOVA as shown in Table 4.

Table 4. Pooled Analysis of Variance for $\mathrm{S} / \mathrm{N}$ ratio for Surface Roughness

\begin{tabular}{|c|c|c|c|c|c|c|c|}
\hline S. No. & Source & $\begin{array}{c}\text { Sum of } \\
\text { Square }\end{array}$ & $\begin{array}{c}\text { Degree of } \\
\text { Freedom }\end{array}$ & $\begin{array}{c}\text { Mean } \\
\text { Square }\end{array}$ & F- ratio & Status & $\begin{array}{c}\text { Percentage } \\
\text { Contribution }\end{array}$ \\
\hline 1. & WIRE TYPE & 8.658 & 2 & 4.329 & 5.051 & Significant & $22.86 \%$ \\
\hline 2. & PULSE ON TIME & 8.249 & 2 & 4.124 & 4.812 & Significant & $21.78 \%$ \\
\hline 3. & PULSE OF TIME & 1.198 & 2 & 0.599 & 0.698 & Insignificant & $3.16 \%$ \\
\hline 4. & PEAK CURRENT & 3.549 & 2 & 1.774 & 2.070 & Insignificant & $9.37 \%$ \\
\hline 5. & SERVO VOLTAGE & 2.710 & 2 & 1.355 & 1.581 & Insignificant & $7.15 \%$ \\
\hline 6. & $\begin{array}{c}\text { WIRE } \\
\text { TENSION }\end{array}$ & 1.907 & 2 & 0.953 & 1.112 & Insignificant & $5.03 \%$ \\
\hline & WIRE FEED RATE & 1.314 & 2 & 0.657 & 0.766 & Insignificant & $3.46 \%$ \\
\hline & ERROR & 10.289 & 12 & 0.857 & & Insignificant & $27.16 \%$ \\
\hline
\end{tabular}

Table 5. Response Table for Signal-To-Noise ratio for Surface Roughness

\begin{tabular}{|c|c|c|c|c|c|c|c|c|c|}
\hline LEVEL & $\begin{array}{c}\text { WIRE } \\
\text { TYPE }\end{array}$ & TON & TOFF & PC & SV & WT & WF & SF & FP \\
\hline 1 & -11.286 & $-9.937^{*}$ & -10.986 & -11.053 & -11.105 & -10.616 & $-10.448^{*}$ & -10.852 & -10.904 \\
\hline 2 & $-9.937^{*}$ & -10.966 & -10.652 & -10.859 & -10.682 & $-10.434^{*}$ & -10.987 & $-10.524^{*}$ & -10.686 \\
\hline 3 & -10.892 & -11.213 & $-10.478^{*}$ & $-10.205^{*}$ & $-10.329^{*}$ & -11.066 & -10.681 & -10.741 & $-10.526^{*}$ \\
\hline DELTA & 1.349 & 1.276 & 0.508 & 0.848 & 0.776 & 0.632 & 0.539 & 0.328 & 0.378 \\
\hline RANK & 1 & 2 & 7 & 3 & 4 & 5 & 6 & 9 & 8 \\
\hline
\end{tabular}

* Larger S/N ratios are better to minimize loss function. 
With pooled error variance, again, only the input factor 'wire type' and 'pulse-on time' shows significance at 5\% level of significance. The response table for signal-to-noise ratio for all the variables is given in Table 5. In the last row of Table 5 ranks have been given to various factors. Higher is the rank, higher is the significance. In the Table 5 wire type has the highest rank 1 and this is the most significant factor followed by pulse-on time with rank 2 . However, the other factors have less effect.

\subsection{Effect of Different Wire Electrodes}

The effect of different wire electrode's materials on surface roughness is shown in Figure2. It shows that the value of surface roughness decreases when wire is changed from plain brass wire to diffused wire and it increases, when the wire is changed from diffused wire to coated zinc wire. Minimum surface roughness was observed with diffused wire and maximum with plain brass wire.

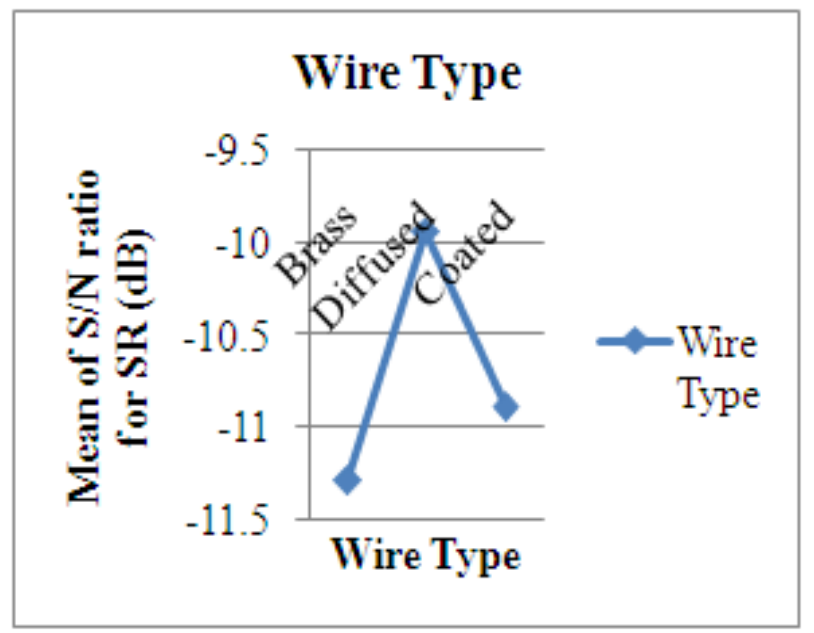

Figure 2. Effect of Wire Type on Surface Roughness

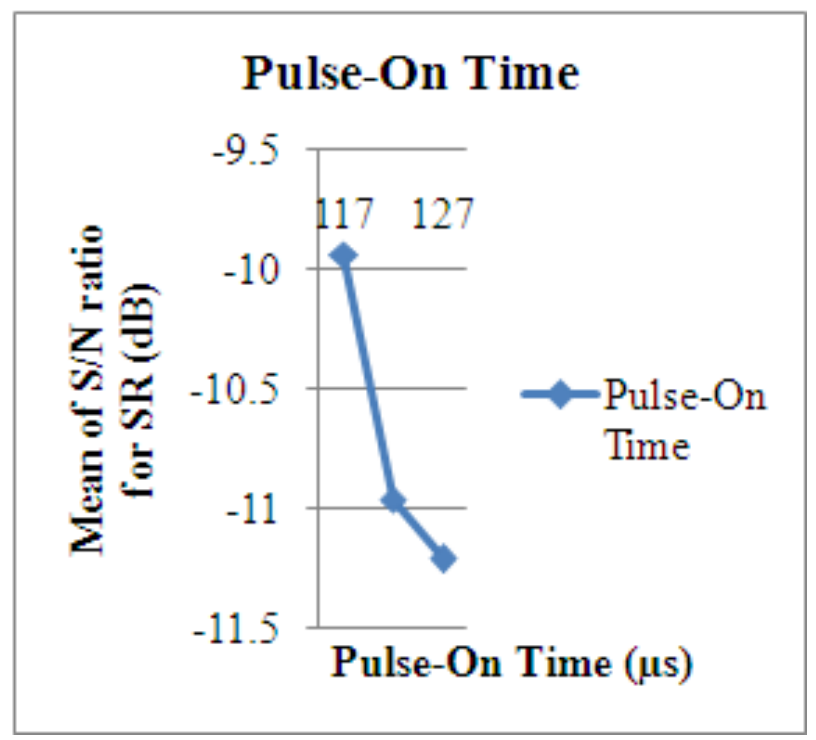

Figur 3. Effect of Pulse-On Time on Surface Roughness

\subsection{Effect of Pulse-On Time}

The effect of varying pulse on time on surface roughness is shown in Figure. 3. It shows that the surface roughness increases with increase in value of pulse-on time. It may be due to increase in pulse current produces stronger spark and higher temperatures. This causes more melting of the material and eroding the workpiece and consequent increase in surface roughness. The results are inline with Muthuraman et al. [8], who conducted experiments to investigate the influences of process variables during Wire Electric Discharge Machining of O1 steel and found that the surface roughness increases with increase in value of pulse on time.

\subsection{Effect of Pulse-Off Time}

The effect of varying pulse off time on surface roughness is shown in Figure 4. It shows that with increased value of pulse off time, the surface roughness decreases. This may be because of higher the value of pulse off time, lesser is the number of discharges in a given time, resulting in non uniform sparking and lesser number of particles disloged near surface of work materials. This causes more hills and valleys rather than uniform rounded surfaces. Similar results have been shown by Subramanyam et al. [9] who conducted experiments for Evalution of optimal parameters for machining with Wire-Cut EDM using Grey-Taguchi method.

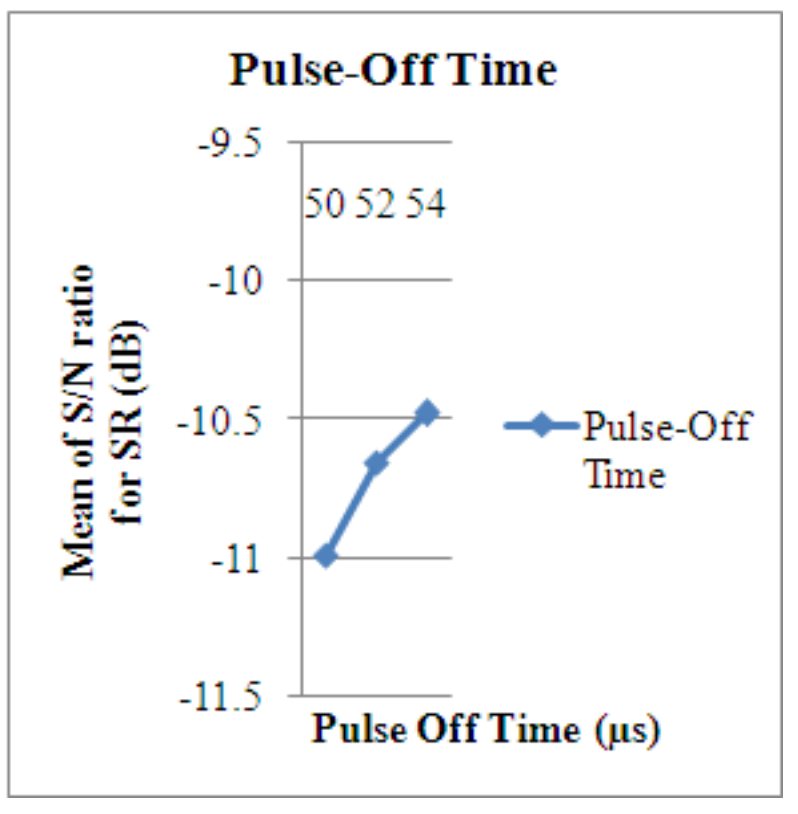

Figure 4. Effect of Pulse Off Time on Surface Roughness

\subsection{Effect of Peak Current}

The effect of varying peak current on surface roughness is shown in Figure 5. It shows that the surface roughness decreases with increase in value of peak current. The results are inline with Subramanyam et al.[9], who conducted 
experiments for Evalution of optimal parameters for machining with Wire-Cut EDM using Grey-Taguchi method and found that the surface roughness decreases with increase in value of peak current.

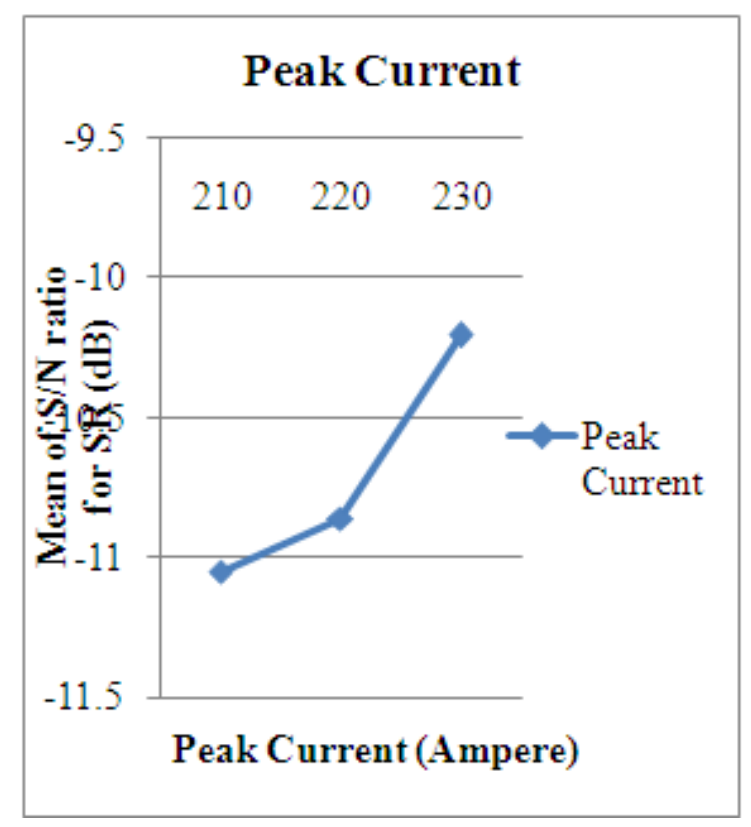

Figure 5. Effect of Peak Current on Surface Roughness

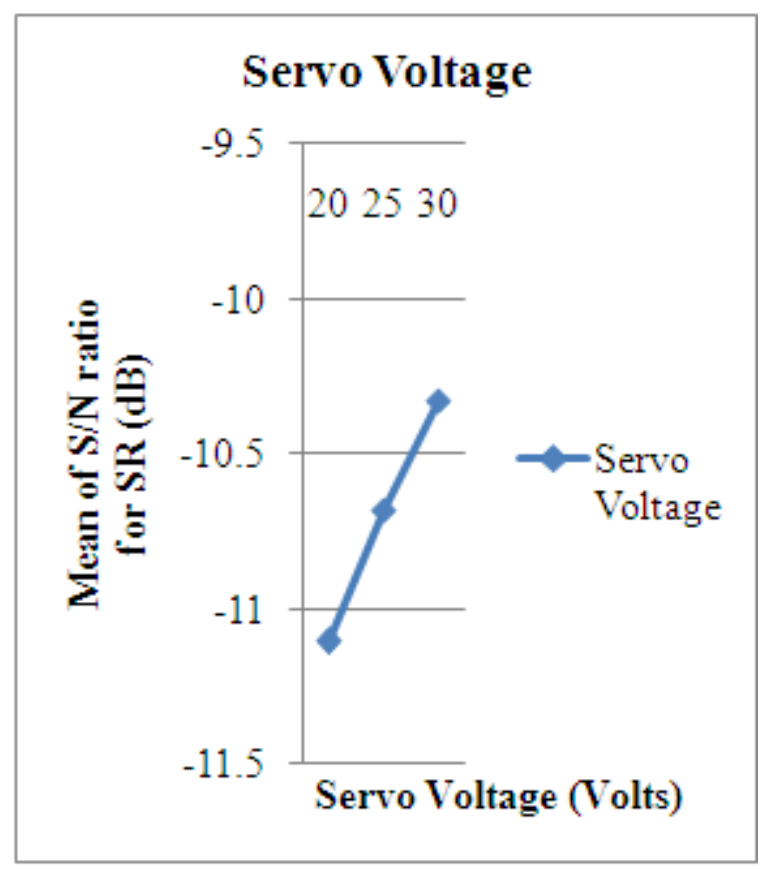

Figure 6. Effect of Servo Voltage on Surface Roughness

\subsection{Effect of Servo Voltage}

The effect of varying servo voltage on surface roughness is shown in Figure 6. It shows that with increase in value of servo voltage, surface roughness decreases. The reason for this may be that when the value for servo voltage is higher; the gap between the workpiece and the electrode becomes wider. Higher value for servo voltage decreases the number of electric sparks, stabilizing electric discharge, although the machining rate is slowed down. When a smaller value is set for servo voltage, the mean gap becomes narrower, which leads to an increase in number of electric sparks. It can speed up the machining rate; however, resulting in poor surface and wire breakage. Similar results have been reported by Muthuraman et al. [8], Rao et al. [5].

\subsection{Effect of Wire Tension}

The effect of varying wire tension on surface roughness is shown in Figure 7. It shows with increase in wire tension, surface roughness first decreases and then increases with more increase in wire tension. Surface roughness did not have much of a variation with the increase in wire tension, though wire tension reduces a vibration and improves the surface quality of the machined part. On the other hand wear ratio has increased linearly with an increase in wire tension. Therefore, with more increased wire tension, the surface roughness has been reduced. Subramanyam et al. [9] conducted an study on evalution of optimal parameters for machining with Wire-Cut EDM using Grey-Taguchi method and similar results were found.

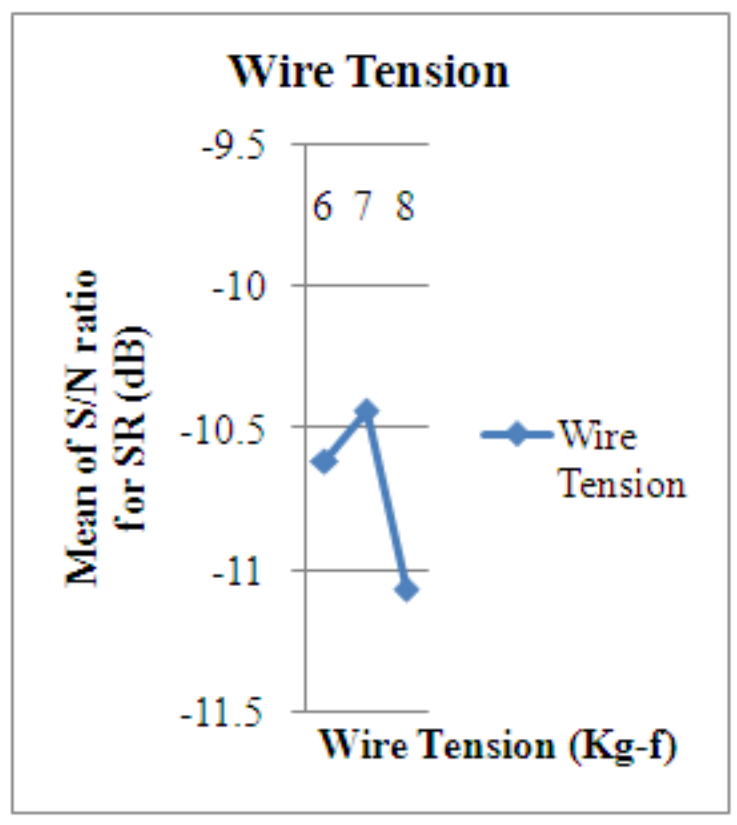

Figure 7. Effect of Wire Tension on Surface Roughness

\subsection{Effect of Wire Feed Rate}

The effect of varying wire feed rate on surface roughness is shown in Figure 8. It shows with increase in wire feed, that surface roughness first increases and then decreases. Wire feed did not play a vital role on surface roughness of the workpiece. On the other hand as the wire feed increased the wear ratio decreased drastically. This is because the spark erosion on the travelling wire electrode becomes thin and brittle with increased feeds. When wire feed is at maximum, 
fresh wire is introduced and the spark generation was also greater. This results in lesser usage of wire electrode. The results are inline with Rao et al. [5], Muthuraman et al. [8] and Subramanyam et al. [9].

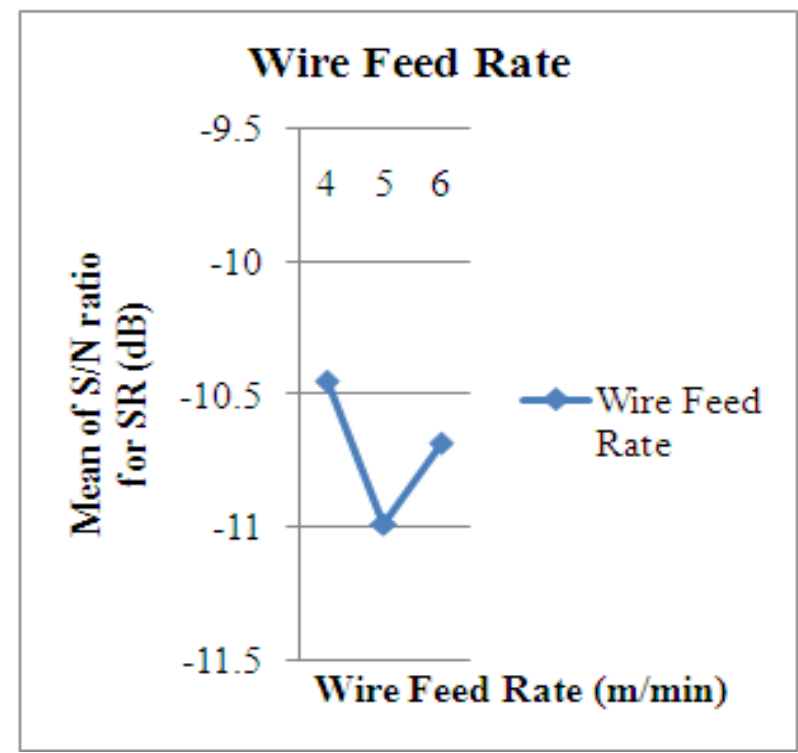

Figure 8. Effect of Wire Feed Rate on Surface Roughness

\subsection{Effect of Servo Feed Rate}

The effect of varying servo feed rate on surface roughness is shown in Figure 9. It shows that with increase in servo feed rate, surface roughness values initially decreases and then increases with further increase in value of servo feed rate. Alias et al. [6] conducted a study on WEDM: Influence of machine feed rate in machining Titanium Ti-6Al-4V using brass wire and constant current $(4 \mathrm{~A})$ and similar results were found.

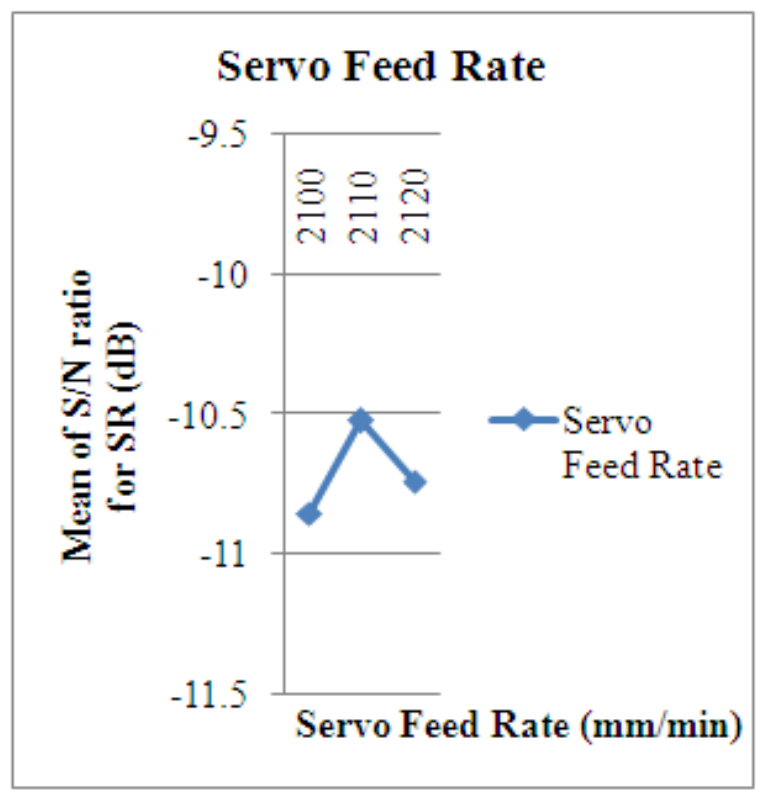

Figure 9. Effect of Servo Feed Rate on Surface Roughness

\subsection{Effect of Flushing Pressure}

The effect of varying flushing pressure on surface roughness is shown in Figure 10. It shows that increase in value of flushing presure decreases the surface roughness. This may be due to the cooling effect of dielectric flow rate on the workpiece surface. The other reason could be that increased flow on the workpiece may prevent debris adhering to the surface. Sufficient flushing pressure is needed for proper functioning.

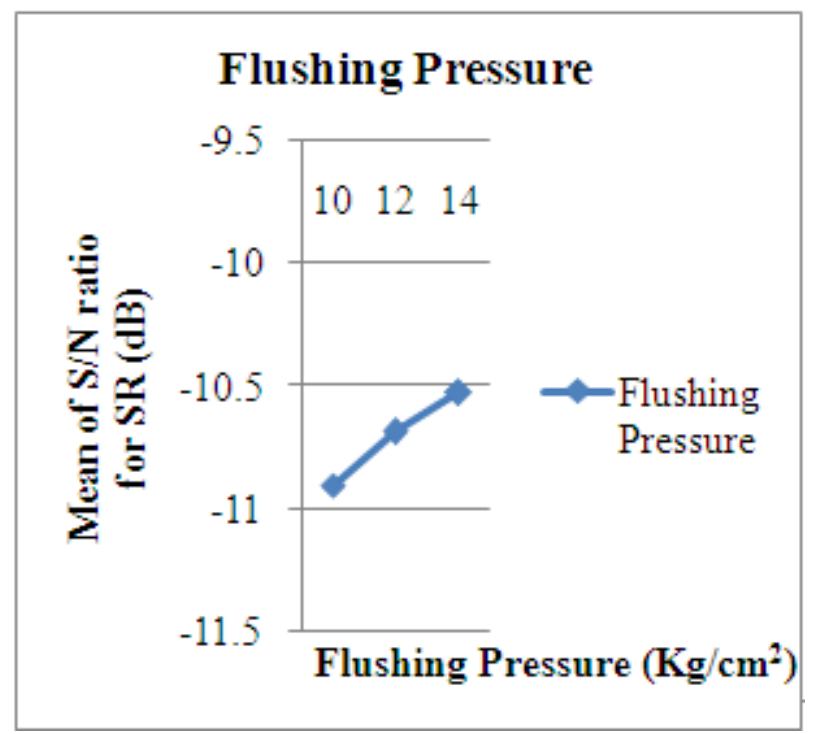

Figure 10. Effect of Flushing Pressure on Surface Roughness

\section{Conclusions}

The wire type, pulse-on time found to be most significant factors for surface roughness, while less effect has been shown by peak current, servo voltage, pulse off time, wire tension, wire feed rate, servo feed rate, flushing pressure on surface roughness. The conclusions of this research work are:

- The surface roughness was found to be minimum with diffused wire and maximum with plain brass wire.

- The surface roughness increases with increase in pulse on time.

- The surface roughness decreases with increase in pulse off time, peak current, servo voltage, and flushing pressure.

- As the wire tension increases, the surface roughness first decreases and then increases with further increase in wire tension.

- As the wire feed rate increases, the surface roughness first increases and then decreases.

- As the servo feed rate increases, the surface roughness initially decreases and then increases with more increase in servo feed rate. 


\section{REFERENCES}

[1] Hascalyk, A., and Caydas, U. Experimental study of wire electric discharge machining of AISI D5 tool steel, Journal of Material Processing Technology, Vol. 148, 362-67, 2004.

[2] Ramakrishnan, R., and Karunamoorthy, L. Modelling and multi-response optimization of Inconel-718 on machining of CNC Wire Electric Discharge Machining process, Journal of Material Processing Technology, Vol. 207, 343-349, 2008.

[3] Yuan, J., Wang, K., Yu, T., and Fang, M. Reliable multi-objective optimization of high speed WEDM process based on Gaussian process regression, International Journal of Machine Tools and Manufacture, Vol. 48, 47-60, 2007.

[4] Singh, H., and Garg, R. Effects of process parameters on material removal rate in Wire Electric Discharge Machining, Journal of Achievements in Materials and Manufacturing Engineering, Vol. 32, No. 1, 70-74, 2009.

[5] Rao, P.S., Ramji, K., and Satyanarayana, B. Effect of WEDM conditions on Surface Roughness: A parametric optimization using Taguchi method, International Journal of Advanced
Engineering Sciences and Technologies, Vol. 6, No. 6, 1041-048, 2011.

[6] Alias, A., Abdullah, B., and Abbas, N.M. WEDM: Influence of machine feed rate in machining Titanium Ti-6Al-4v using Brass wire and constant current(4A), Procedia Engineering, Vol. 41, 1812-1817, 2012.

[7] Sivakiran, S., Reddy, C. B., and Reddy, C. E. Effect of process parameters on material removal rate in Wire Electric Discharge Machining of EN-31 steel, International Journal of Engineering Research and Applications, Vol. 2, No. 6, 1221-1226, 2012.

[8] Muthuraman, V., Ramakrishnan, R., Karthikeyan, L., and Praveen, C. Influences of process variables during Wire Electric Discharge Machining of O1 steel, European Journal of Scientific Research, Vol. 79, No. 3, 2371-77, 2012.

[9] Subrahmanyam, S.V., Sarcar, M.M.M. Evaluation of Optimal Parameters for machining with Wire-Cut EDM using Grey-Taguchi method, International Journal of Scientific and Research Publications, Vol. 3, No. 3, 1-9, 2013 